\title{
Assessing the social cost of housing projects on the built environment: Analysis and monetization of the adverse impacts incurred on the neighbouring communities
}

\author{
Tolga Çelik $^{\mathrm{a}, *}$, Yusuf Arayici ${ }^{\mathrm{b}}$, Cenk Budayan ${ }^{\mathrm{c}}$ \\ ${ }^{a}$ Department of Civil Engineering, Eastern Mediterranean University, Famagusta, T.R. North Cyprus, Via Mersin 10, Turkey \\ ${ }^{\mathrm{b}}$ Department of Civil Engineering, Hasan Kalyoncu University, Gaziantep, Turkey \\ ${ }^{\mathrm{c}}$ Department of Civil Engineering, Yildiz Technical Univserity, Istanbul, Turkey
}

\section{A R T I C L E I N F O}

\section{Keywords:}

Social cost

Social cost definition

Social cost quantification

Construction adverse impacts

Housing projects

Built environment

Neighbouring community

\begin{abstract}
A B S T R A C T
Construction projects generate serious environmental adverse impacts on the adjacent residents. All those harmful consequences and damages that third parties or the community sustain due to the implementation of construction processes are called social costs. Although, the presence of social costs is widely mentioned in the literature, in the projects' initial cost estimation practices, the social costs are not estimated and included. Whereas since these costs are not compensated, problems can be emerged by the community. It is a truism that the majority of the models proposed to quantify the social costs have been concentrated on construction, repair, and maintenance of the infrastructure projects namely; utilities, roads, and highways. On the other hand, up to the present, a limited number of attempts has been made to quantify residential housing construction associated social costs. Thus, this research aims to expand and/or contribute to the existing body of knowledge via estimating how much social cost society surrounding residential housing construction sites are subjected to. For this purpose, a social cost estimation model is developed to assist industry professionals on how to estimate social costs in residential construction projects. The social cost estimation model is developed to provide guidance for phase by phase monetization of the residential construction associated social costs. In this paper, the model proposed for social cost estimation is validated via a case study in Turkey.
\end{abstract}

\section{Introduction}

The developed and developing countries perform extensive construction activities to sustain economic growth (Osei, 2013). However, construction projects can lead to adverse impacts on the ecological, sociological and economic systems of their neighbouring community (Abidin, 2010; Balaban, 2012). Especially, the residents and businesses in proximity to construction projects performed in urban areas can be affected intensively because of the high density of population (Çelik et al., 2017; Ferguson, 2012; Gangolells et al., 2009). These inevitable causative adverse impacts, such as health risks, depression, family conflict, negative social behaviour, urban violence, and employability on the daily routines of the society, is called "social costs" (Apeldoorn, 2013; Boyce and Bried, 1998; Environmental Operations Unit, 2012). These costs can be due to location, isolation, densities, insalubrious conditions and below standard minimum functional dimensions of spaces. Although the reality and presence of the social costs are widely mentioned and encompassed in theory, they are generally ignored and not estimated during project bid evaluation practices (Gilchrist and Allouche, 2005), since in the traditional practices, the construction projects are evaluated as successful based on three criteria, namely cost, time and quality (Bowen et al., 2012). Whereas ignorance of the social costs can lead to the emergence of the public objection. Therefore, the society can show resistance against the construction of the projects by performing protests and opening lawsuits. This public objection can lead to delays and budget overruns ( $\mathrm{Yu}$ and Lo, 2005; Zhou et al., 2017). In addition, the exclusion of the social cost on the project cost estimation can lead to miscalculation of total costs of the construction projects to society, therefore the importance of utilization of new environment-friendly construction methods and technologies cannot be understood completely (Matthews et al., 2015).

Emergence of the social costs as an inevitable and inherent case for construction projects inspired many researchers to come up with numerous approaches to identify the potential adverse impacts exposed to

\footnotetext{
* Corresponding author.

E-mail address: tolga.celik@emu.edu.tr (T. Çelik).
} 
communities surrounding construction sites and to evaluate the cost of those impacts (Allouche et al., 2000; Gilchrist and Allouche, 2005; Read and Vickridge, 2004; Yu and Lo, 2005; Yuan et al., 2013). However, the quantification of social cost in construction projects is a difficult and complex process (Apeldoorn, 2013; Gilchrist and Allouche, 2005; Yu and Lo, 2005), therefore it is impossible to develop a general formula for all types of construction projects. Consequently, in the existing body of knowledge, scholars worked on predicting the equivalence of the adverse impacts exposed to third parties neighbouring a construction site where infrastructure construction, repair or maintenance works are carried out. Up to the present performed approaches promote contractors to compensate the social costs through incorporating them into bid evaluation. In this way, contractors are motivated to perform more rational planning of the construction methods. This can be interpreted as: public who are the beneficiaries of infrastructure projects and who indirectly fund the projects are inevitably incurred by the social costs borne by the execution of the projects. Thus, infrastructure projects need to be justified in terms of the sustainable construction methods to the public (Yeow and Feltham, 2008). For compensation purposes, it is reasonable to consider the social cost as a component of initial project cost and evaluate it in the bidding.

On the other hand, a limited number of attempts are made to estimate the social costs emerged due to the impacts of construction of residential housing projects. In majority of the residential housing construction projects, the beneficiaries are private investors instead of public whereas the social costs are inevitably incurred on the public. Although a surrounding community is potentially not the financer of the project and is not the beneficiary of the output, owners of the project and contractors must somehow and in some way justify their construction methods and make any necessary compensations to the community. Proposal of social cost estimation model can if not directly, at least indirectly enforce contractors to justify their construction methods just as the contractors of public projects to eliminate the social costs and if not eliminated, to compensate them to public in an applicable way. Lack of such a model puts developing countries such as North Cyprus and Turkey in a worse situation as their building code of practices and construction regulations do not enforce the contractors for considering sustainable construction methods/applications to mitigate incurrence of social costs on the public.

In the literature, the adverse impacts of infrastructure projects incurred on the third parties are monetized (Ferguson, 2012). However, the measurement and quantification of social costs is complicated process due to the lack of paradigm for practice used for the classification and assessment of the social costs in a feasible way (Rahman et al., 2005). In addition, in the grand scheme of things, existing approaches have not managed to go beyond conjecture in providing a phase by phase road map to be followed by professionals so that they can monitor/measure the actual effects of construction activities on the third parties.

It is noteworthy to highlight the importance of measuring alterations in one's routine since when these alterations can be measured, the impacts of the construction can easily be enumerated and monetized. Hence, attributed to the project under development in the format of "social cost". As the definition of the social cost implies that these are the construction-oriented nuisances that are incurred on the third parties. It is a must to incorporate them into social cost estimation. This can provide opportunity to justify how accurate our scholarly hypothesis match with their real-life practice. In this way, conducting indirect superficial assumptions on behalf of them can be by-passed. Therefore, the model proposed in this paper arrays steps on how to include third parties and estimate social costs.

In the literature, the importance of sustainable construction is widely emphasized. Sustainability has four pillars that should be considered in sustainable development. These are social sustainability, physical sustainability, economic sustainability and environmental sustainability. Sustainable construction should also incorporate these four pillars for its sustainable development. Although economic (e.g. capital cost, lifecycle cost), physical (e.g. quality) and environmental sustainability (e.g. waste, energy) dimensions are considered, social sustainability is hardly considered in the sustainable construction literature. Thus, this paper also addresses an important gap by highlighting the social dimension of sustainability in construction. In other words, sustainable construction perspective itself entails the consideration of social cost estimation to contribute to the social sustainability in construction.

In this study, a social cost estimation model that standardizes the quantification of the social costs of the construction of the residential housing projects is proposed in accordance with the definition of the social costs. Therefore, a new model, which literally measures the perceived nuisance based on the alterations in the daily routine of the third parties, is proposed. This model can be useful to estimate social cost in residential constructions in North Cyprus and Turkey, where the building permission regulations are not strict, and contractors do not pay enough attention to lessen or eliminate the occurrence of adverse impacts. Finally, having estimated the residential construction associated social costs, a model should be developed to apply in practice.

\section{Externality principle in the fundamental economic theory}

The effects of construction of residential buildings on the neighbouring community are widely stated in this study although the neighbouring community is the third party and they do not have any control over the factors that affect the construction process and are not directly related to the production and consumption. In the literature, this is defined as externality by the economists. The externality and its quantification is widely discussed in the literature, and there are many studies especially related to environmental pollution, e. g. carbon pollution (Nordhaus, 2014), environmental valuation (Matthews and Lave, 2000), since the externality perspective is considered as the most logical way to examine the environmental pollution (Verschueren, 2001). Externalities are considered as an important form of market failure since their existence leads to a deviation from the Pareto efficiency, in which the price mechanism take cares of efficient resource allocation. Based on Pareto optimality, when all exchanges of goods between economic actors have taken place, this is identified by the impossibility of a reallocation of goods that would not leave at least one actor worse off. The exchanges between the economic actors must be voluntary. To achieve this voluntariness, the parties should gain an advantage from this exchange (Campbell, 2016). However, due to the externalities, the third parties are not voluntarily involved in and cannot gain advantage. Therefore, market prices do not reflect full social costs (Verschueren, 2001). For instance, more than $30 \%$ of the estimated automobile costs are considered as external costs and these costs are subsidized by the society since these costs are not included in the appraisal of automobile costs (Mareddy, 2017). This is also valid for construction too when contractor does not compensate the negative externalities, neighbouring communities has to pay for the cost of negative externalities.

Although social cost of infrastructure projects is discussed in the literature, no advantages as positive externalities are created for neighbouring communities. However, there is a possibility to reach a Pareto optimality in these projects without any statutory intervention. Neighbouring communities cannot gain advantage from a construction project, especially in a developed residential locations. Hence, negative externalities are more dominant in residential projects compared to the infrastructure projects, which in turn leads to difficulties to attain an optimum without a statutory intervention.

To internalize the externality in the market, it can be tradable (LWc, 2007), which is achieved when the externality is quantified. Otherwise, optimum level of economic activity cannot be determined since the cost of this externality is not known. Pigou (1932) proposed that the government should intervene directly through centralized instruments by quantity regulations (bans) and monetary tools (taxes or subsidies) 
to eliminate or compensate the negative external effects. However, the benefit of reduced harm can be obtained only at a cost. Coase (1960) criticized this approach due to the consideration of one direction of the externality and lack of its reciprocal nature. Based on Coase theorem, Campbell (2016) stated that only focusing on harm prevention and regarding environmental policy without economic considerations is fundamentally mistaken. Coase (1960) proposed that the optimal level can be established as the automatic result of bargaining by the involved parties regardless of which party is ultimately awarded the property rights. Stigler (1966) considered a factory, which spews smoke on thousand homes and proposed that the ideal solution is to arrange a compensation system, whereby the homeowners pay the factory owner to smoke reduction devices up to the point where the marginal cost of smoke reduction equals to the sum of marginal gains to homeowners. The opposite ideal solution can also be valid; in this solution the factory owner compensates the losses of the neighbouring community since the compensation can be more profitable than installing a smoke reduction device. To determine the best optimal solution, the marginal gains of homeowners should be calculated. However, he also stated that due to the high transaction cost, a statutory intervention may be feasible. Coase (1959) also supported special regulations for dealing the smoke pollution since it is more difficult to reach a satisfactory solution through the market when there are many harmed people and several sources of pollution.

\section{Quantification of social cost}

The quantification of social costs is a set of procedures followed to evaluate the cost of construction originated adverse impacts. There are different approaches proposed in the literature. However, these approaches are composed of similar procedures for the evaluation of social costs. These approaches are generally developed by considering the adverse impacts of the infrastructure projects. For instance, Gilchrist and Allouche (2005) proposed a model to quantify social costs of the infrastructure projects taking place in urban environments by considering 22 sources of social costs and categorized these sources into four main categories, namely the impact on the community, economy, environment and public property. Yu and Lo (2005) focused on the road construction causative adverse impacts and developed a model. Similarly, Jiang et al. (2010) quantified excess user costs at work zones by including the delay costs; such as deceleration, reduced speed, acceleration and vehicle queue delay cost; and additional vehicle operating costs due to reduction of available lanes. On the other hand, Florez et al. (2012) focused on the pavement rehabilitation of highways and evaluated the adverse impacts of pavement rehabilitation activities on neighbouring community via identifying road user and agency costs. Liu et al. (2013) developed a decision model by using intuitionistic fuzzy group for bid evaluation of infrastructure projects considering social costs. They evaluated the effects of six aspects of social cost by experts' group character and fuzziness. Another attempt for quantifying the infrastructure projects is performed by Matthews et al. (2015) and they presented mathematical methods for calculating the eight social cost categories of pipeline infrastructure projects. A different effort for quantification of social cost was performed by Zhou et al. (2017) that used emergy analysis method to quantify social cost of large-scale projects. They calculated social cost of each stage of a project and concluded that the social costs should also be included in the total project cost estimation.

Establishing a standardization for the evaluation of infrastructure associated social costs and proposing a method to compensate is a major common address of previously proposed approaches. Yet, it is still necessary to propose a pragmatic way to monetize residential construction associated social costs. Therefore, there is a need for an elaborative study that gathers factors of residential construction associated social costs to provide an imminent social cost figure for a specific construction project.

\section{Research epistemology}

Research adopts positivism as research epistemology since it studies what is clear, factual and open to observation (Pring, 2004). Saunders et al. (2016) and Gill and Johnson (2010) stated that the positivistic stance is applied through collecting data about an observable reality and by searching for regularities and causal relationships within the selected data to create law-like generalisations. With the positivism stance, impact of construction projects on the surroundings can be observed with the credible mathematical data.

In the positivistic research, the researchers can use the existing knowledge to develop hypotheses. In turn, these hypotheses can be tested and either confirmed or refuted, leading to further development of theory, which may then be tested by the future research (Rombach et al., 1993). Similarly, our research in this project research is formally informed from the previous research and knowledge on social cost phenomenon and builds the hypothesis for sustainability and externalities principles in residential construction in North Cyprus and Turkey then aims to test the hypothesis of the social cost estimation model to be confirmed as a theory.

The underlying philosophy is to quantify residential building causative social costs in urban areas by measuring the change in standard of the third parties' possessed assets in terms of the reactions given by them to bring the standard of their assets back to its original state. Therefore, a social cost estimation model is developed.

In the next section, paper is structured in accordance with the research process in Fig. 1 for the development and implementation of the social cost estimation model.

\section{Research methodology}

Triangulation strategy is applied as the overall research strategy to ensure the reliability and validity of the research through adopting multi-methods for data collection, analysis and validation. Research methods and techniques such as focus group study, case studies and questionnaire based survey are adopted to perform in the research process, depicted in Fig. 1, reflecting the key stages for data collection, analysis and validation.

Research process has six stages for the development of the social cost estimation model. These are:

- Stage 1: Identification of Social Cost Types via Literature review and desktop analysis.

- Stage 2: Identification of Social Cost Components via Focus Group Study and Case Studies

- Stage 3: Identification of Social Cost Sub-components via Focus Group Study and Case Studies

- Stage 4: Identification of Perceived Nuisances via Questionnaire based Survey

- Stage 5: Specification of the Social Cost Estimation Model via Focus Group Studies

- Stage 6: Implementation and Validation of the Model via Questionnaire based Survey

These stages and research development in these stages are considered under two parts. First part is related to the development of methodological framework, the second part is implementation of the proposed social cost. These parts are elaborated as follows:

\subsection{Development of methodological framework}

\subsubsection{Stage 1: identification of the social cost impact types}

Desktop study for in-depth literature review is performed for identifying the types of social cost impact. Different social cost impact types are proposed in the literature. As mentioned before, Gilchrist and Allouche (2005) identified the four main categories of social costs 


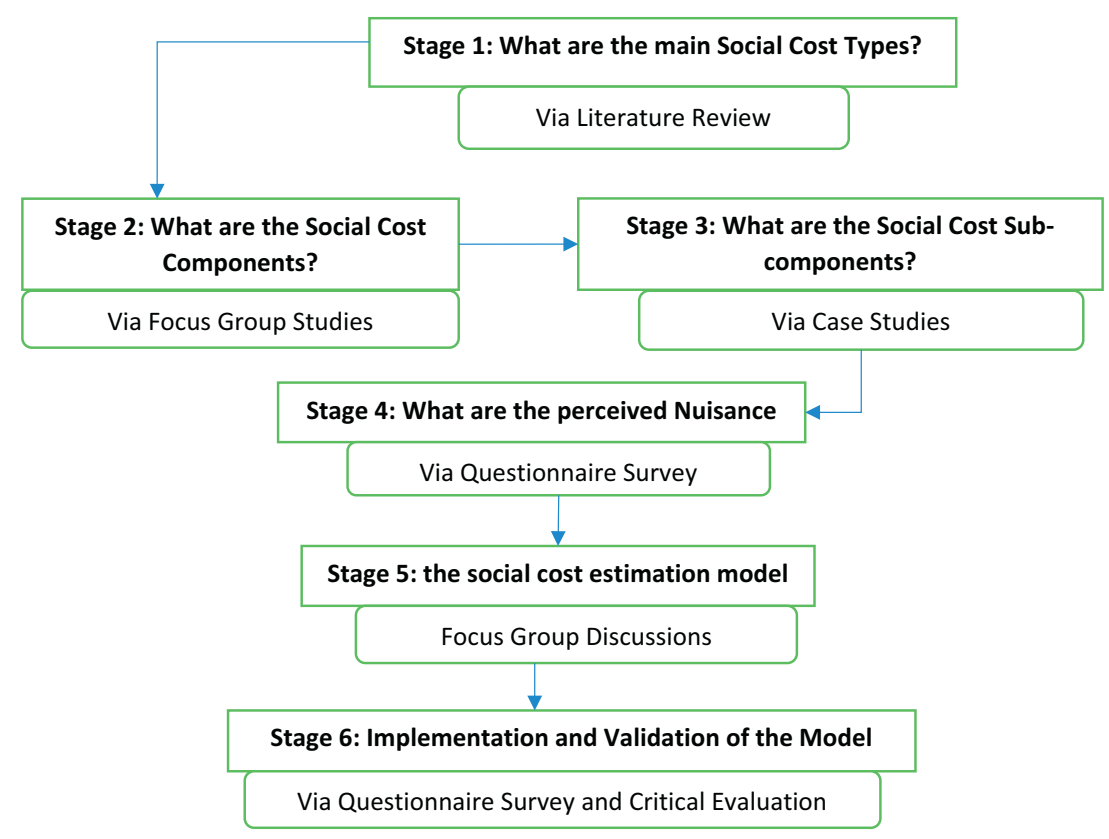

Fig. 1. Research process design.

according to their impacts. Similarly, according to Yuan et al. (2013), 11 social costs on residential buildings can be categorized into four main categories, namely the impact on the community, economy, environment and public property. Matthews et al. (2015) categorized social cost in eight important groups for pipeline infrastructure projects.

It is noteworthy that social costs occurring because of executing construction projects do not show immense variations. According to United States Environmental Protection Agency (1995)'s report, construction sites accommodating heavy construction works are the sources of dust emissions causing temporary impact locally. In other words, it leads to formation of the social costs in the neighbouring community.

In this report, building and road constructions are shown as the two common sources of local pollution in terms of dust due to execution of construction activities. Land clearing, drilling and blasting, ground excavation, earthworks and construction of a facility are associated as the similar activities to cause local pollution regardless to the type of construction projects in progress (infrastructure, non-infrastructure). For that reason, the social cost parameters identified for infrastructure construction associated activities in the literature and among them the ones that are compatible within the limitations of this research are benefitted in this phase. Consequently, by considering the studies (Apeldoorn, 2013; Ferguson, 2012; Gilchrist and Allouche, 2005; Lee et al., 2005; Matthews et al., 2015; Najafi and Gokhale, 2005; Yu and Lo, 2005; Yuan et al., 2013) conducted for other construction projects, residential building-borne adverse impacts are identified. The clusters of these adverse impacts are determined as; damage to natural and built environment, pollution and traffic problems.

Alterations in the daily routine of construction site's surrounding community during the development phases of construction projects are essentially the social cost indicators. Measuring the intensity and frequency of each itemized daily alteration contributes to the revealing process of social costs associated with the residential construction. Thus, it is crucial to primarily identify the adverse impacts to pave the way for itemizing alterations in the daily routine of residents. Hence, measuring the consequences residing near a residential construction site is required.
5.1.2. Stage 2: identification of social cost components via focus group study

Initially, the main goal of the focus group is the identification of the components that are exposed to construction adverse impacts with the main lines. Subsequently, target audience considering professional including environmental impact assessor, local authority environmental problems and complaints department representatives, engineers and town planners and residents of developing areas of major cities are selected upon their availability. Initially, the participants of the focus group study are briefed about the social cost phenomenon, then answers of the participants are recorded on the video and essential information are analysed by organizing discussions into categories.

It is asserted from the focus group study that in the existing practice, the construction causative adverse impacts types are firstly segregated and the social cost indicators of each adverse impact type are then determined. Social costs are then evaluated for the indicators identified. However, due to an inherent correlation among the identified social cost indicators, proposed approaches are considered as ambiguous and complex for accurate estimation.

It is asserted that difficulty in evaluating the project social costs can be minimized through segregating the impact types of the social costs with respect to community's possessed components. The life quality can be measured by evaluating a variety of determinants including physical being, psychological being, and physical belongings (Raphael et al., 1996). Especially, physical belongings are related to the connections with the physical environments of home, workplace, neighbourhood, school and community. Thereby, it is interpretable that when these physical belongings are exposed to causative adverse impacts, people are ready to make additional payments for resolving or mitigating the perceived impairment to preserve their quality of life.

By considering the findings obtained from literature review and brainstorming sessions in the focus group studies, the third parties are identified as social cost components: households, house and neighbourhood. Accordingly, a social cost equation is proposed as Eq. (1) shown below for the social cost components. In Eq. (1), $\mathrm{SC}_{\mathrm{LR}}$ is social cost for local residents, $\mathrm{SC}_{\mathrm{N}}$ is social cost for neighbourhood, $\mathrm{SC}_{\mathrm{HH}}$ is social cost for households and $\mathrm{SC}_{\mathrm{H}}$ is Social cost for house/car(s).

$\mathrm{SC}_{\mathrm{LR}}=\mathrm{SC}_{\mathrm{N}}+\mathrm{SC}_{\mathrm{HH}}+\mathrm{SC}_{\mathrm{H}}$ 
Table 1

Case study projects used in the research for the social cost estimation model development.

\begin{tabular}{|c|c|c|c|c|c|c|c|}
\hline & Proj. & Proj. type & Commencement & \# of participants & Budget (\$) & Size & Number of floor \\
\hline \multirow[t]{4}{*}{ Kyrenia } & $\mathrm{P} 1$ & Residential & September 2011 & 20 & $9 \mathrm{M}$ & $12,000 \mathrm{~m}^{2}$ & 15 \\
\hline & $\mathrm{P} 2$ & Residential & December 2011 & 23 & $10,4 \mathrm{M}$ & $8550 \mathrm{~m}^{2}$ & 5 \\
\hline & P3 & Residential & April 2011 & 19 & $1,52 \mathrm{M}$ & $1950 \mathrm{~m}^{2}$ & 4 \\
\hline & P4 & Residential & January 2012 & 20 & $4,3 \mathrm{M}$ & $5200 \mathrm{~m}^{2}$ & 8 \\
\hline \multirow[t]{3}{*}{ Nicosia } & P5 & Residential & January 2012 & 24 & $3,7 \mathrm{M}$ & $4800 \mathrm{~m}^{2}$ & 5 \\
\hline & P6 & Residential & March 2012 & 21 & $2,2 \mathrm{M}$ & $2850 \mathrm{~m}^{2}$ & 6 \\
\hline & P7 & Residential & March 2012 & 30 & $8 \mathrm{M}$ & $9500 \mathrm{~m}^{2}$ & 8 \\
\hline \multirow[t]{3}{*}{ Famagusta } & P8 & Residential & February 2012 & 31 & $790 \mathrm{~K}$ & $940 \mathrm{~m}^{2}$ & 3 \\
\hline & P9 & Residential & February 2012 & 26 & $1,8 \mathrm{M}$ & $2300 \mathrm{~m}^{2}$ & 4 \\
\hline & P10 & Residential & December 2011 & 26 & $5,1 \mathrm{M}$ & $6050 \mathrm{~m}^{2}$ & 6 \\
\hline Istanbul & $\mathrm{P} 11$ & Residential & May 2015 & 54 & $18,4 \mathrm{M}$ & $35,000 \mathrm{~m}^{2}$ & 12 \\
\hline
\end{tabular}

5.1.3. Stage 3: identification of social cost sub-components via case studies Observations from case studies and the participatory experiences in case studies are the techniques used for collecting data for the identification of the eight sub-components (measurable indicators). Initially, current trend and practices in the targeted construction industries are examined. Afterwards, descriptive and reflective notes about researchers' visual observation, auditory perception and what has experienced is considered for the analysis.

Specification of the social cost sub-components and identification of perceived nuisance criteria are achieved through the exemplifying cases where the investigated elements broadly showed the existence of the social cost theory. List of the case studies used in the research are given in Table 1 below.

At this stage, the subcomponents of each social cost components are identified by segregating the social cost components and an equation is proposed to calculate each social cost components with the measurable subcomponents. These measurable subcomponents are identified via the case studies and explained below.

5.1.3.1. Neighbourhood subcomponents. The four subcomponents are proposed for the neighbourhood component, and these subcomponents are:

- Cost of traffic problems ( $\mathrm{C}_{\mathrm{TP}}$ : Cost of Traffic Problem)

- Cost of car parking space problems ( $\mathrm{C}_{\mathrm{CP}}$ : Cost of Car Parking)

- Cost of deficiency in using recreational facilities of neighbourhood $\left(\mathrm{C}_{\mathrm{RF}}\right.$ : Cost of Recreational Facilities)

- Cost of alterations in the ambient standard of neighbourhood $\left(\mathrm{C}_{\mathrm{AS}}\right.$ : Cost of Ambient Standard)

Eq. (2) is proposed for calculating the social cost of neighbourhood by including these subcomponents.

$\mathrm{SC}_{\mathrm{N}}=\mathrm{C}_{\mathrm{TP}}+\mathrm{C}_{\mathrm{CP}}+\mathrm{C}_{\mathrm{RF}}+\mathrm{C}_{\mathrm{AS}}$

5.1.3.2. Households subcomponents. Three subcomponents of households are proposed and these subcomponents are:

- Cost of having problems in meeting daily necessities $\left(\mathrm{C}_{\mathrm{DN}}\right.$ : Cost of Daily Necessities)

- Cost of maintaining standard health /personal care $\left(\mathrm{C}_{\mathrm{HP}}\right.$ : Cost of Health/Personal Care)

- Cost of limitations in the use of outdoors $\left(\mathrm{C}_{\mathrm{LO}}\right.$ : Cost of Limited use of Outdoors)

Based on these, Eq. (3) is proposed to calculate the social cost related to household.

$\mathrm{SC}_{\mathrm{HH}}=\mathrm{C}_{\mathrm{DN}}+\mathrm{C}_{\mathrm{HP}}+\mathrm{C}_{\mathrm{LO}}$

5.1.3.3. House/car subcomponents. The subcomponents of house and car are determined as below:

- Cost of additional pollution of the outdoor areas of the house $\left(\mathrm{C}_{\mathrm{OC}}\right.$ : Cost of Outdoor Cleaning)

- Cost of additional pollution of the indoor areas of the house $\left(\mathrm{C}_{\mathrm{IC}}\right.$ : Cost of Indoor Cleaning)

- Cost of additional pollution of the cars $\left(\mathrm{C}_{\mathrm{CW}}\right.$ : Cost of Car Wash)

The cost of maintaining the standards of house and cars can be calculated by these components. Thus, the equation is proposed to calculate the social cost to maintain standards for house and car.

$\mathrm{SC}_{\mathrm{H}}=\mathrm{C}_{\mathrm{OC}}+\mathrm{C}_{\mathrm{IC}}+\mathrm{C}_{\mathrm{CW}}$

\subsubsection{Stage 4: identification of perceived nuisance criteria via questionnaire} survey

In this study, omnipresent nuisance parameters are considered to propose a social cost estimation equation for measuring the additional costs on the local residents. However, values of these parameters cannot be calculated without conducting a field survey at the geographical location of the construction project so that the parameters, which start out a reaction in people nearby, can be identified due to the presence of omnipresent nuisances. These parameters should be identified carefully since different cultures and social manners between communities lead to different types of social costs.

A field survey is performed in North Cyprus and Turkey to identify the perceived nuisances on residents neighbouring the construction sites. Four cities, namely Nicosia, Famagusta, Kyrenia in North Cyprus, and Istanbul in Turkey are selected for this field survey. Participants for these surveys were selected according to having resided within $150 \mathrm{~m}$ of a distance to a residential building construction site since additional construction dust formation is shown to significantly disturb the residents within $150 \mathrm{~m}$ of a construction site (Watkins, 1981).

By using the Google map, the apartments placed within $150 \mathrm{~m}$ to a residential building construction site are numbered from 1 by following a circle. Firstly, the nearest circle to the construction site is numbered, and then the outer circles are numbered from 1 . Therefore, each circle creates a stratum. In other words, sampling is performed by using stratified random sampling. The survey is started from apartment 1 from the first circle, all of the households at apartment 1 are informed about the survey by a visit and asked to participate in the survey. After completing the surveys of the apartment, the survey is conducted for every third apartment, which means that the second survey is conducted at apartment 4 . This process is performed for all of the strata. Therefore, at the second stage of sampling, the systematic sampling method is applied. A total of 320 questionnaire surveys are collected at the end of this field survey at a return rate of $41.03 \%$.

In the conducted questionnaire $52.26 \%$ of the respondents were men, and $47.74 \%$ of the respondents were women. Therefore, the views of both genders about the incurrence of social costs to residents are considered. Also, according to the age groups and their distributions 
Table 2

Demographic structure of the respondents.

\begin{tabular}{lll}
\hline & & Percentage \\
\hline \multirow{2}{*}{ Gender of the respondents } & Male & $52.26 \%$ \\
& Female & $47.74 \%$ \\
& $18-24$ & $22.56 \%$ \\
& $25-33$ & $24.06 \%$ \\
& $34-44$ & $21.43 \%$ \\
& $45-54$ & $15.04 \%$ \\
& $55-65$ & $12.41 \%$ \\
& 66 and over & $4.51 \%$ \\
& Literate & $0.38 \%$ \\
& Primary school & $16.17 \%$ \\
& Secondary school & $7.89 \%$ \\
& High school & $34.59 \%$ \\
& Vocational high school & $0.38 \%$ \\
& Undergraduate & $25.94 \%$ \\
& Master degree & $3.01 \%$ \\
& Doctorate degree & $11.65 \%$ \\
\hline
\end{tabular}

shown in Table 2, the views of different age groups are used to capture the all ideas from the community.

Lastly, education levels of the respondents are examined. Although the majority of the respondents are graduated from high school (34.59\%), the other respondents have different education levels. Therefore, the views of the respondents from different equation levels are also included into this study. Consequently, these figures indicate that this study reveals the different views from different demographical backgrounds.

According to the conducted field survey, 17 different nuisance criteria are identified. Subsequently, pre-identified social cost components are used to categorize these designated nuisance criteria and each criterion is associated with the abovementioned social cost sub-components. Table 3 shows the lists of criteria for the perceived nuisances identified.

The cost estimation of a construction project requires the identification of all parameters affecting the project and the above stated parameters representing social cost sub-components. The communities intrinsically show different reactions to resolve/mitigate the negative changes on their life due to the adverse impacts of construction activities. Thus, the construction causative nuisances on third parties should be identified for each community and there cannot be a standard generalization. In other words, surveys are required to estimate the costs of the manpower, equipment, machinery, material and expenses such as head-office overheads locally. Likewise, the local surveys should be performed to identify the local nuisance criteria to quantify the social costs monetarily.

\subsubsection{Stage 5: the social cost estimation model}

At this stage, findings developed accumulatively from the previous stages for the social cost estimation model are consolidated to develop a Social Cost Estimation Model depicted in Fig. 2. This figure displays variety of functions in a logical sequence and prioritize the derivation process of the proposed standardized social cost estimation equations. This model is adopted for the quantification of social costs and findings are presented in the following sections.

Defining nuisance criteria acquired at stage 4 is an important link to monetize probable alterations in the daily routine. Due to the nature of this research, conducting a questionnaire is necessary as the most convenient tool for performing this enumeration. For instance, in stage 4 additional pollution of the car(s) is recognized as a common nuisance criterion. The quantification of this nuisance criterion requires additional number of the car wash during construction to clean up their cars. However, this information can only be obtained by questioning the surrounding community via questionnaire survey.

To quantify each nuisance criteria, a unique empirical equation should be developed for each nuisance criteria. Accumulating the quantified entire nuisance criteria perceived by residents via implementing the developed equations will output the social costs. Eq. (5), encapsulating Eqs. (2), (3), and (4), is proposed for this purpose. Therefore, Eq. (5) shown below is the final equation to estimate the social cost.

$$
\begin{aligned}
\mathrm{SC}_{\mathrm{LR}}= & {\left[\mathrm{C}_{\mathrm{TP}}+\mathrm{C}_{\mathrm{CP}}+\mathrm{C}_{\mathrm{RF}}+\mathrm{C}_{\mathrm{AS}}\right]+\left[\mathrm{C}_{\mathrm{DN}}+\mathrm{C}_{\mathrm{HP}}+\mathrm{C}_{\mathrm{LO}}\right] } \\
& +\left[\mathrm{C}_{\mathrm{OC}}+\mathrm{C}_{\mathrm{IC}}+\mathrm{C}_{\mathrm{CW}}\right]
\end{aligned}
$$

\subsection{Implementation of the proposed social cost estimation model}

To test the practicability of the proposed social cost estimation model, set of field surveys within $150 \mathrm{~m}$ proximity to construction projects are performed in Turkey. In this section, how the typical social costs emerged due to the construction of the residential construction projects are quantified is explained.

\subsubsection{Measuring the effects of nuisances perceived by the local residents}

Another questionnaire survey is conducted in the nearby of Project 11 in Istanbul to measure the consequences of perceived nuisances on residents. 54 surveys are conducted within the $150 \mathrm{~m}$ vicinity of the project. Daily routine alterations of these 54 residents are enumerated and equivalence of their alterations in monetary units for social cost estimation is carried out.

Participants of the questionnaire are initially asked if there were any alterations in their daily routine because of being exposed to the

Table 3

The lists of criteria for the perceived nuisances identified

\begin{tabular}{ll}
\hline Social cost Sub-components & Perceived nuisance criteria \\
\hline $\mathrm{C}_{\mathrm{TP}}$ & - Lessened road safety standards of the neighbourhood $\left(\mathrm{C}_{\mathrm{TP}(1)}\right)$ \\
& - Road pollution of the neighbourhood $\left(\mathrm{C}_{\mathrm{TP}(2)}\right)$ \\
& - Alterations in standard flow of traffic in the neighbourhood $\left(\mathrm{C}_{\mathrm{TP}(3)}\right)$ \\
$\mathrm{C}_{\mathrm{CP}}$ & - Car parking space problems in the area $\left(\mathrm{C}_{\mathrm{CP}(1)}\right)$ \\
$\mathrm{C}_{\mathrm{RF}}$ & - Lessened serviceability standards of the playfields/parks/hiking trails $\left(\mathrm{C}_{\mathrm{RF}(1)}\right)$ \\
$\mathrm{C}_{\mathrm{AS}}$ & - Additional pollution of the ambient / neighbourhood $\left(\mathrm{C}_{\mathrm{AS}(1)}\right)$ \\
& - Lack of serviceability of the habitat/parks $\left(\mathrm{C}_{\mathrm{AS}(2)}\right)$ \\
$\mathrm{C}_{\mathrm{DN}}$ & - Alterations in standard peace and quietude of the neighbourhood $\left(\mathrm{C}_{\mathrm{AS}(3)}\right)$ \\
$\mathrm{C}_{\mathrm{HP}}$ & - Alterations in meeting daily necessities $\left(\mathrm{C}_{\mathrm{DN}(1)}\right)$ \\
$\mathrm{C}_{\mathrm{LO}}$ & - Alterations in standard health/well-being/personal care $\left(\mathrm{C}_{\mathrm{HP}(1)}\right)$ \\
$\mathrm{C}_{\mathrm{OC}}$ & - Limitations in the use of outdoors $\left(\mathrm{C}_{\mathrm{LO}(1)}\right)$ \\
& - Additional pollution of the walls of the house $\left(\mathrm{C}_{\mathrm{OC}(1)}\right)$ \\
$\mathrm{C}_{\mathrm{IC}}$ & - Additional pollution of the house's yard $\left(\mathrm{C}_{\mathrm{OC}(2)}\right)$ \\
& - Additional pollution of the house $\left(\mathrm{C}_{\mathrm{IC}(1)}\right)$ \\
$\mathrm{C}_{\mathrm{CW}}$ & - Additional pollution of the curtains $\left(\mathrm{C}_{\mathrm{IC}(2)}\right)$ \\
\hline
\end{tabular}




$\begin{gathered}\text { Social cost } \\ \text { impact types }\end{gathered}$
$\begin{gathered}\text { Impact } \\ \text { on }\end{gathered}$
$\quad \begin{gathered}\text { Social cost sub- } \\ \text { components } \\ \text { Social cost } \\ \text { components }\end{gathered}$

Fig. 2. Paradigm of the social cost estimation model.

Table 4

The weighted daily alterations of perceivable nuisance criteria and their social cost estimates.

\begin{tabular}{|c|c|c|c|c|c|}
\hline \multirow{2}{*}{$\begin{array}{l}\text { Associated social cost } \\
\text { Sub-components }\end{array}$} & \multirow{2}{*}{$\begin{array}{l}\text { Rate of participants who have } \\
\text { altered their daily routine (\%) }\end{array}$} & \multicolumn{3}{|l|}{ Type of daily alteration } & \multirow{2}{*}{$\begin{array}{l}\text { Generated social cost } \\
(£ / \text { day/house) }\end{array}$} \\
\hline & & $\begin{array}{l}\text { Additional cleaning } \\
\text { (person-hour/month) }\end{array}$ & $\begin{array}{l}\text { Additional distance } \\
\text { travelled (kms/month) }\end{array}$ & $\begin{array}{l}\text { Additional miscellaneous } \\
\text { (actions/month) }\end{array}$ & \\
\hline $\mathrm{C}_{\mathrm{TP}(1)}$ & 61.6 & & 36 & & 0.13 \\
\hline $\mathrm{C}_{\mathrm{TP}(2)}$ & 65.6 & & 46 & & 0.16 \\
\hline $\mathrm{C}_{\mathrm{TP}(3)}$ & 66.8 & & 66 & & 0.23 \\
\hline $\mathrm{C}_{\mathrm{CP}(1)}$ & 42.9 & & 45 & & 0.11 \\
\hline $\mathrm{C}_{\mathrm{RF}(1)}$ & 61.9 & & 64 & & 0.20 \\
\hline $\mathrm{C}_{\mathrm{AS}(1)}$ & 71.0 & & 56 & & 0.18 \\
\hline $\mathrm{C}_{\mathrm{AS}(2)}$ & 66.8 & & 62 & & 0.21 \\
\hline $\mathrm{C}_{\mathrm{AS}(3)}$ & 71.1 & & 81 & & 0.29 \\
\hline $\mathrm{C}_{\mathrm{DN}(1)}$ & 58.7 & & 42 & & 0.14 \\
\hline $\mathrm{C}_{\mathrm{HP}(1)}$ & 45.0 & & & $\begin{array}{l}2.1 \text { (residents visit to a } \\
\text { doctor/specialist) }\end{array}$ & 0.90 \\
\hline $\mathrm{C}_{\mathrm{LO}(1)}$ & 85.0 & & & $93 \mathrm{~h}$ (air-conditioning usage) & 0.85 \\
\hline $\mathrm{C}_{\mathrm{OC}(1)}$ & 69.2 & 3.8 & & & 0.36 \\
\hline $\mathrm{C}_{\mathrm{OC}(2)}$ & 60.9 & 1.9 & & & 0.17 \\
\hline $\mathrm{C}_{\mathrm{IC}(1)}$ & 79.3 & 5.8 & & & 0.62 \\
\hline $\mathrm{C}_{\mathrm{IC}(2)}$ & 69.2 & 7.0 & & & 0.68 \\
\hline $\mathrm{C}_{\mathrm{IC}(3)}$ & 73.4 & 4.8 & & & 0.48 \\
\hline $\mathrm{C}_{\mathrm{CW}(1)}$ & 72.6 & & & 1.66 (car wash) & 0.54 \\
\hline
\end{tabular}

nuisances. This paves the way to obtain more accurate results for the estimation of the social costs. For instance, $50 \%$ of the residents stated that they were adversely affected by perceivable nuisance criteria. Then, the estimated cost for these criteria, which is to be incurred on the residents, is halved.

Afterwards, alterations in the daily routine of the residents concerning each social cost sub-component are obtained via the questionnaire with respect to three categories namely; additional cleaning (man hour/month), additional distance travelled (kilometres/month) and additional miscellaneous actions performed in a month. Numbers representing the alterations in the daily routine of the residents, which shed light on the estimation of the generated social costs, are given by Table 4.

On the other hand, for two types of daily alteration categories; additional distance travelled and additional cleaning, the two examples are worked out below to demonstrate the quantification, where the numbers stated in Table 4 falling into these categories come from.

\subsection{Category; alterations in daily routine in terms of additional cleaning}

Example 1 - Additional pollution of the house's yard (COC(2));

It should be known that calculation of the additional cleaning in terms of person-hour/month for the relevant social cost sub-components, respondents are asked to state the time required to fulfil each activity (each social cost sub-component). For example, they indicated that activity to clean the yard of the house takes about $22 \mathrm{~min}$. This shed light on calculating the approximate additional cleaning performed with respect to $\mathrm{C}_{\mathrm{OC}(2)}$ during the construction in terms of person-hours/month as follows;

- Participants stated that before the construction they used to maintain the standard cleanliness of their house yards by getting cleaned approximately 17.33 times (mean value) in a month. However, during the construction, this number has increased to about 22.24 times showing that residing near a construction site led them to perform 4.91 times additional cleaning in their house yards.

- Responses of the participants indicate that it takes averagely $22 \mathrm{~min}$ to clean the yard of their house hence, it works out by $4.91 \times 22$ that each month there is an additional 108.02 min of cleaning in house yards.

Numbers given in Table 4 and representing the rest of the social cost sub-components falling into this category are worked out in the same manner.

\subsection{Category; alterations in daily routine in terms of additional distance travelled}

Example 2 - The method used in the transportation departments are modified for calculation of costs emerged due to additional distance travelled. Additional distance travelled as a result of alterations in standard flow of traffic in the neighbourhood $\left(\mathrm{C}_{\mathrm{TP}(3)}\right)$;

It should be known that when calculating additional distance travelled for the relevant social cost sub-components, respondents are asked to state frequency of each activity (each social cost sub-component) fulfilled in a day. For instance, they indicated that during the construction in their neighbourhood, they have averagely attempted 7 times to detour/deviate their routine way to avoid traffic congestion problems. This shed light on calculating the approximate additional distance travelled with respect to $\mathrm{C}_{\mathrm{TP}(3)}$ during the construction in terms of kilometres/month as follows;

- Participants stated that during the construction in their neighbourhood, each time they detoured/deviated due to traffic congestions they had to travel additional $300 \mathrm{~m}$ (mean value).

- Having indicated that they have detoured/deviated approximately 7 times in a day, it works out by $7 \times 300$ that each day they have additionally travelled $2100 \mathrm{~m}$ in a day. 
The statement mentioned in the previous example is valid for this example.

\subsubsection{Estimation of the social costs}

The social costs are estimated through the five experiential equations that are made up of the social cost estimation model, which are given below. In estimation of the social cost, local unit rates obtained from North Cyprus State and Planning Organization (2014) are used for the implementation of the equations. In a point of fact, the developed experiential equations are the sub-equations of Eq. (2) $\left(\mathrm{SC}_{\mathrm{N}}\right), 3\left(\mathrm{SC}_{\mathrm{HH}}\right)$, and $4\left(\mathrm{SC}_{\mathrm{H}}\right)$, which are used to calculate Eq. (5) $\left(\mathrm{SC}_{\mathrm{LR}}\right)$.

\subsubsection{Experiential equation for the quantification of indoor/outdoor house nuisances}

The nuisances due the additional pollution of the construction of the residential building is quantified by considering the cost of cleaning up the additional dirt and an equation is developed as follows and this equation is used for quantifying the different nuisances of the dirt on the indoor/outdoor of the house, therefore a new symbol, $C_{m s c}$, is used instead of the symbols stated in Tables 3 and 4.

$C_{m s c}=W_{c} \times T_{c} \times N_{a c} \times \frac{1}{60} \times \frac{1}{30} \times A \%$

where, $\mathrm{C}_{\mathrm{msc}(\mathrm{n})}$ means daily cost of cleaning up the additional dirt, (n) is used to give a number for the output of each different criterion; $\mathrm{W}_{\mathrm{c}}$ is hourly wage of cleaner in pounds and is obtained from North Cyprus State Planning Organization; $T_{c}$ is time required for cleaning in minutes and the value of this parameter is obtained from the questionnaire survey; $\mathrm{N}_{\mathrm{ac}}$ is number of additional cleaning performed in a month and this is also obtained from the questionnaire survey; $\mathrm{A} \%$ is percentage of the residents who have altered their daily routine (applied to all the perceivable nuisance criteria in accordance with the numbers given in Table 4). $\frac{1}{60}$ is also added to the equation to convert the time required for performing each criterion from minutes to hours. Finally, $\frac{1}{30}$ is added to the equation, since the number of additional cleaning performed is responded on monthly basis. Therefore, this number is should be converted to the daily basis.

As stated before, this equation can be used to quantify different nuisances, therefore $\mathrm{C}_{\mathrm{OC}(1)}$ is calculated via implementing experiential Eq. (6). The values of the parameters are determined as $W_{c}=£ 4.15 / \mathrm{h}$, $\mathrm{T}_{\mathrm{c}}=66.4 \mathrm{~min}$ and $\mathrm{N}_{\mathrm{ac}}=3.36$ for $\mathrm{C}_{\mathrm{OC}(1)}$ and $\mathrm{C}_{\mathrm{OC}(1)}$ is calculated as $£ 0.36 /$ day.

Estimation of the generated social costs concerning $\mathrm{C}_{\mathrm{OC}(2)}, \mathrm{C}_{\mathrm{IC}(1)}$, $\mathrm{C}_{\mathrm{IC}(2)}, \mathrm{C}_{\mathrm{IC}(3)}$ are carried out in the same manner.

\subsubsection{Experiential equation for the quantification of Car wash $\left(C_{c w}\right)$ nuisance}

This equation is also developed to assist the estimation of $\mathrm{C}_{\mathrm{cw}}$ and it is as follows;

$C_{c w}=P_{c w} \times N_{a c w} \times N_{o c} \times \frac{1}{30} \times A \%$

Where $\mathrm{P}_{\mathrm{cw}}$ means the price of a car wash in pounds and it is determined as $£ 10$ and $N_{o c}$ is number of cars held per each house, these values of the parameters are obtained from North Cyprus State Planning Organization; $\mathrm{N}_{\mathrm{acw}}$ is number of additional car washes in a month and this value is obtained from the questionnaire as 1.66 .

This equation is applied for estimation of $\mathrm{C}_{\mathrm{CW}}$ in North Cyprus. According to the North Cyprus State and Planning Organization (2014), there is an average of 1.34 car per each house in North Cyprus. According to the experiential Eq. (7), average daily money spent by the residents of each house is calculated as $£ 0.54$ /day.

\subsubsection{Experiential equation for the quantification of neighbourhood nuisances}

Some of the nuisances can lead to the additional travel distance, for instance due to closure of some roads or excess traffic in the neighbourhood residents may have either difficulty or no chance in finding a convenient on street car parking space in their area. Therefore, they have to perform additional travel to find a convenient parking space. This equation is developed to assist the estimation of cost of additional distance travel by considering the extra fuel consumption and it is as follows;

$C_{A D T(n)}=D_{a t} \times C_{a p} \times P_{o f} \times N_{a t} \times \frac{1}{1000} \times A \%$

where $\mathrm{C}_{\mathrm{ADT}(\mathrm{n})}$ means daily cost of additional distance travelled, (n) is used to give a number for the output of each different criterion; $D_{a t}$ is additional distance travelled in a day (in meters); $\mathrm{N}_{\mathrm{at}}$ is number of times the activity repeated in a day. The values of $\mathrm{D}_{\mathrm{at}}$ and $\mathrm{N}_{\mathrm{at}}$ are obtained from the questionnaire. $\mathrm{C}_{\mathrm{ap}}$ is average petroleum consumption of the car per $\mathrm{km}$, this value is obtained from observations depending on the size of the cars used in the country and experience; $P_{\text {of }}$ is Average price of fuel ( $£$ /liters), the value of this parameter is obtained from North Cyprus State Planning Organization; $\frac{1}{1000}$ is used as a conversion factor (kilometres/m).

To give an example of how this equation is used, $\mathrm{C}_{\mathrm{TP}(1)}$ is calculated. The values of parameters of Eq. (8) for $C_{\mathrm{TP}(1)}$ are $\mathrm{D}_{\mathrm{at}}=240 \mathrm{~m}$, $\mathrm{C}_{\mathrm{ap}}=0.125 \mathrm{l} / \mathrm{km}, \mathrm{P}_{\text {of }}=£ 1.15 / 1, \mathrm{~N}_{\mathrm{at}}=6 /$ day, and $\mathrm{C}_{\mathrm{TP}(1)}$ is calculated as $£ 0.13 /$ day.

Since $\mathrm{C}_{\mathrm{TP}(2)}, \mathrm{C}_{\mathrm{TP}(3)}, \mathrm{C}_{\mathrm{DN}(1)}, \mathrm{C}_{\mathrm{AS}(1)}, \mathrm{C}_{\mathrm{AS}(2)}, \mathrm{C}_{\mathrm{AS}(3)}, \mathrm{C}_{\mathrm{RF}(1)}, \mathrm{C}_{\mathrm{CP}(1)}$ nuisances can be eliminated by traveling additional distance, the generated social costs concerning these nuisances can be estimated by using the developed equation in the same manner. However, although the same equation can be used, the values of variables of the equation can vary highly.

\subsubsection{Experiential equation for the quantification of household nuisances}

This equation is developed to assist the estimation of cost of alterations in standard health/well-being/ personal care $\left(\mathrm{C}_{\mathrm{HP}}\right)$ and it is as follows;

$C_{H P}=P_{v d s} \times N_{o v} \times \frac{1}{30} \times A \%$

where $\mathrm{P}_{\mathrm{vds}}$ is average price of visiting a doctor/specialist and the value for this parameter is obtained from North Cyprus State Planning Organization as $£ 30 ; N_{o v}$ is additional number of visits to a doctor/ specialist and this value is obtained from the questionnaire as 2.0.

This equation is applied for estimation of $\mathrm{C}_{\mathrm{HP}}$ in North Cyprus and it is calculated as $£ 0.90 /$ day.

\subsubsection{Experiential equation for the limited outdoor use $\left(C_{L O}\right)$}

In this study; it is assumed that $\mathrm{C}_{\mathrm{LO}}$ can be calculated based on daily cost of extra air- conditioning usage, since the residents have to spend more time inside and use air conditioner to maintain the room temperature, especially in hot region countries, such as Turkey and Cyprus, this additional usage of air-conditioning is leading additional cost on the residents. The following equation is developed to assist the estimation of $\mathrm{C}_{\mathrm{LO}}$.

$C_{L O}=C_{a e} \times P_{e} \times U_{a a} \times A \%$

$\mathrm{C}_{\mathrm{ae}}$ is average electricity consumption of air conditioners per hour, and there is no secondary data about the value of this parameter, therefore the value of this parameter is obtained through observations as $1.5 \mathrm{~kW} / \mathrm{h} ; \mathrm{P}_{\mathrm{e}}$ is electricity cost per $\mathrm{kw}$, the value for this parameter is obtained from North Cyprus Electricity Administration as $£ 0.22 / \mathrm{kW}$; $\mathrm{U}_{\mathrm{aa}}$ is additional air-conditioning usage hours/day, and the value for this parameter is obtained from the questionnaire as $3.02 \mathrm{~h} /$ day.

It is remarkable that $17.91 \%$ of the respondents do not have air conditioners fitted at their houses, but if they had, they would have utilized it. Consequently, for evaluation of the "A\%" value, the respondents, of this case are also incorporated in the analyses. 
Consequently, $\mathrm{C}_{\mathrm{LO}}$ is calculated as $\mathrm{C}_{\mathrm{LO}}=£ 0.85 /$ day.

5.4.7. Estimation of the social cost/day incurred to the local residents $\left(S C_{L R}\right)$

Based on the findings of the questionnaire survey, alterations in the residents' daily routine are enumerated and development/implementation of the abovementioned experiential equations contributed greatly for the estimation of the social costs of the residential building for North Cyprus and Turkey.

Within this context, for this specific case, by implementing the Eq. (5)

$\left(\mathrm{SC}_{\mathrm{LR}}=\left[\mathrm{C}_{\mathrm{TP}}+\mathrm{C}_{\mathrm{CP}}+\mathrm{C}_{\mathrm{RF}}+\mathrm{C}_{\mathrm{AS}}\right]+\left[\mathrm{C}_{\mathrm{DN}}+\mathrm{C}_{\mathrm{HP}}+\mathrm{C}_{\mathrm{LO}}\right]+\left[\mathrm{C}_{\mathrm{OC}}+\mathrm{C}_{\mathrm{IC}}\right.\right.$ $\left.+\mathrm{C}_{\mathrm{CW}}\right]$ ), social cost/day/house incurred on residents living near a construction site are calculated as $£ 6.25$. In which social cost subcomponents do variables used during the calculation belong to is illustrated in Table 4 under generated social costs section.

Finally, 54 people in 27 houses located within $150 \mathrm{~m}$ distance of each construction site is determined in this study. Considering this information, for this specific case, total social costs generated from a construction to a neighbourhood is calculated as $£ 168.75$.

\section{Discussions}

The social cost estimation model proposed arrays the steps to be followed by professionals revealing how to incorporate the society and estimate the costs incurred to them. Social costs are expressed for every functioning day of a construction site due to difficulties and complexities in defining them activity wise. On the other hand, based on engineering experience, observations, and studies performed in literature (United States Environmental Protection Agency, 1995; Yuan et al., 2013), it is asserted that resultant nuisances due to execution of construction activities do not show immense variations with respect to building construction preference (i.e. RC framed building, Steel framed building).

This study lights the way for professionals by proposing a comprehensive social cost estimation system composed of a framework that assists them on how to obtain the building construction related social costs.

With literature review, focus group, case studies and questionnaire survey performed in North Cyprus and Turkey by 320 locals, three categories of social cost components; namely house, households and neighbourhood, are identified and 17 different perceivable nuisance criteria are identified.

According to the survey, these nuisances are perceived as the most important nuisances altering the daily routine of the local residents within $150 \mathrm{~m}$ proximity. These nuisances are the actual external effects of the residential construction projects. Therefore, they should be compensated by contractor or eliminated by the local residents nearby and the expenses used to eliminate or compensate these external effects is considered as the social cost from those construction projects.

How these nuisances are eliminated by households are considered to calculate the social costs. The additional pollution created by the construction projects is eliminated by performing additional cleaning. When the cost of additional cleaning is calculated, the social cost of this external effect can be quantified. Few of these nuisances can be eliminated by traveling additional distances. The additional traveling distance is also considered as an external effect and can be used for quantifying the social cost of nuisances.

Additional miscellaneous are considered to calculate the social cost for health problems and the limited outdoor usage. Due to the construction activities related environmental pollution such as; noise, dust, dirt, debris, and/or spillages of materials, and the time that residents use outdoor areas of their houses to maintain their comfort in the sense of leisure and fresh air. If the residents cannot use that time for outdoor, the usage of air-conditioning inside is increased, which in turn leads to incurrence of the additional costs on residents. In addition, health problems due to the residential construction projects can cause residents visiting health clinics for health problems. Therefore, the cost of these visits is also considered for quantification of external effect. Consequently, the social cost model includes five experiential equations proposed for the residential construction projects.

Alterations in the daily routine of 54 local residents within the proximity of $150 \mathrm{~m}$ to the construction site in Project 11 are enumerated to form a basis for estimating the social costs by using local unit rates and proposed equations. The total social cost is obtained as $£ 6.25 /$ day/house and on average $£ 168.75 /$ day/building construction site in Project 11 for example. This amount also shows that there is a direct relationship between the duration of the residential construction and the social cost. Thus, factors, such as complexity and size of the projects affecting the project durations should also be considered for the social cost quantification.

The calculated daily amount is remarkable. In addition, the number of positive externalities is very limited in residential building projects compared to the infrastructure projects. Therefore, the "socially efficient equilibrium" is not attainable by the market, and the residents are highly suffered from the social cost. Thus, a tax or quota should be imposed to correct this suffer and move output closer to the level of social efficiency.

A new social cost compensation method can be considered that a contractor can be the responsible body to defray the social costs on local residents within $150 \mathrm{~m}$ proximity that are affected by the construction activities. In this method, an instrument, a type of surety bond, can be thought and named as "social cost bond". So, the contractor is enforced to provide another type of bond to the client as a performance bond or a payment bond. The client will provide this social cost bond to the municipality while having the residential building permission. The amount of the social cost bond would be estimated by the municipality using the social cost estimation model proposed in the paper.

This social cost bond can be used as a bargaining tool. As stated by Coase (1960), if there is no transaction cost, the parties can attain the most beneficial terms to both parties by bargaining and negotiating. However, Stigler (1966) stated that the transaction cost can be prohibitive of having people together, of assessing damages and so on, when the number of parties exposed to the external effects of an economic transaction is numerous. However, after submitting this bond, the contractor has to reconsider the construction methods and management of the project to minimize, if not totally avoid, the generation of the social costs by calculating the marginal cost. The contractor prefers the social cost reduction methods up to the point, where the marginal cost of these methods equals to the social cost bond. Any incurred social costs will be compensated by municipality via social cost bond submitted. Consequently, contractor performs necessary negotiation inside the organization to reach the optimum point.

\section{Conclusions}

There is a limited number of studies about the social costs in the construction industry in the literature. Some researchers such as (Boyce and Bried, 1998; Environmental Operations Unit, 2012; Gilchrist and Allouche, 2005) proposed different methods to quantify and compensate the social costs in some infrastructure projects, and these projects are placed outside the residential areas. Therefore, the effects of construction on the residents are generally ignored or considered limitedly. This study proposed a method for quantifying the social costs of a building construction site in residential areas and recommends a method of compensating it to community.

The aim is to monetize the social costs of the residential building. However, this is not an easy process, since it is a time consuming and long-lasting study, which in turn lead to some limitations. Three potential limitations of the current research study, stated below, deserve attention and the future research could extend the findings by 
addressing its current limitations.

I. The social costs are quantified in terms of per day. However, this quantification in terms of per activity can be also considered since the social costs can be assigned to the activity costs separately in the planning system and the timely cash flow of construction can be obtained more accurately and practically.

II. The proposed equation is alleged to be commonly applicable by means of collecting values of designated parameters locally. By considering the locally driven cultural and people's social manner variations, enhanced accuracy is obtainable for the quantification procedure.

III. The questionnaires are conducted in this study by visiting houses only. Therefore, the findings of this study are based on the perception of the house residents. This study can be developed by including the commercial premises too.

IV. The findings of this study are specific to building construction sites in residential areas. Therefore, the other studies should be performed by following the procedures suggested in this study for different construction types, such as infrastructure projects in residential areas.

V. This study concentrates on the short-term nuisances of the new residential buildings, especially nuisances emerged throughout the construction phase. However, some nuisances can emerge after construction, such as permeant traffic congestion, car parking problems and permeant noise. Therefore, this study can be developed by including the social cost in the life cycle cost of residential buildings.

However, the proposed nuisance criterions and proposed empirical equations to enumerate them cannot be globally applicable due to set of variables: (1) differences in countries' building code of practices and construction regulations; (2) perception of people for the construction activities related nuisances and the reaction given against very much varies based on culture, the way of living, and fastidiousness of the community; (3) from region to region, construction projects vary with the economic social and political conditions; (4) availability of construction technology, materials, and other resources. Therefore, the nuisance criterions determined in this research are proposed to be applicable specifically for the residential building construction industry.

\section{References}

Abidin, N.Z., 2010. Investigating the awareness and application of sustainable construction concept by Malaysian developers. Habitat Int. 34, 421-426. https://doi.org/10. 1016/j.habitatint.2009.11.011.

Allouche, E., Ariaratnam, S., AbouRizk, S., 2000. Multi-dimensional utility model for selection of a trenchless construction method. Proc. Constr. Congr. VI 543-553.

Apeldoorn, S., 2013. Trenchless Versus Traditional-Comparing Costs. vol. 38. SASTT. IMIESA, pp. 55-57.

Balaban, O., 2012. The negative effects of construction boom on urban planning and environment in Turkey: Unraveling the role of the public sector. Habitat Int. 36, 26-35. https://doi.org/10.1016/j.habitatint.2011.05.003.

Bowen, P., Cattel, K., Hall, K., Edwards, P., Pearl, R., 2012. Perceptions of time, cost and quality management on building projects. Australas. J. Constr. Econ. Build. 2, 48-56. https://doi.org/10.5130/AJCEB.v2i2.2900.

Boyce, G., Bried, E., 1998. Social Cost Accounting for Trenchless Projects. North American No-Dig. vol. 98. pp. 2-12.

Campbell, D., 2016. Ronald Coase's 'the problem of social cost'. Univ. Queensland law J. 35, 75-98.

Celik, T., Kamali, S., Arayici, Y., 2017. Social cost in construction projects. Environ. Impact Assess. Rev. 64, 77-86. https://doi.org/10.1016/j.eiar.2017.03.001.

Coase, R.H., 1959. The federal communications commision. J. Law Econ. 2, 1-40.

Coase, R.H., 1960. The problem of social cost. J. Law Econ. 56, 837-877. https://doi.org/ $10.1086 / 674872$.

Environmental Operations Unit, 2012. Environmental Awareness for Civil Construction Projects. Transport SA, Walkerville.

Ferguson, A., 2012. Qualitative Evaluation of Transportation Construction Related Social Costs and their Impacts on the Local Community. The University of Texas at Arlington, Texas.
Florez, L., Irizarry, J., Castro-Lacouture, D., Abdollahipour, S., Jeong, H., 2012. Feasibility of implementing a computer-assisted pavement rehabilitation decision support system. Int. J. Constr. Educ. Res. 8, 281-300. https://doi.org/10.1080/ 15578771.2012.658960.

Gangolells, M., Casals, M., Gassó, S., Forcada, N., Roca, X., Fuertes, A., 2009. A methodology for predicting the severity of environmental impacts related to the construction process of residential buildings. Build. Environ. 44, 558-571. https://doi.org/10. 1016/j.buildenv.2008.05.001.

Gilchrist, A., Allouche, E.N., 2005. Quantification of social costs associated with construction projects: state-of-the-art review. Tunn. Undergr. Space Technol. 20, 89-104. https://doi.org/10.1016/j.tust.2004.04.003.

Gill, J., Johnson, P., 2010. Research Methods for Managers, 4th ed. Sage, London.

Jiang, Y., Chen, H., Li, S., 2010. Determination of contract time and incentive and disincentive values of highway construction projects. Int. J. Constr. Educ. Res. 6, 285-302. https://doi.org/10.1080/15578771.2010.521540.

Lee, E.B., Ibbs, C.W., Thomas, D., 2005. Minimizing total cost for urban freeway reconstruction with integrated construction/traffic analysis. J. Infrastruct. Syst. 11, 250-257. https://doi.org/10.1061/(ASCE)1076-0342(2005)11:4(250.

Liu, B., Huo, T., Wang, X., Shen, Q., Chen, Y., 2013. The decision model of the intuitionistic fuzzy group bid evaluation for urban infrastructure projects considering social costs. Can. J. Civ. Eng. 40, 263-273. https://doi.org/10.1139/cjce-2012-0283.

LW-c, Lai, 2007. 'The problem of social Cost': the Coase theorem and externality explained: using simple diagrams and examples to illustrate the role of land use planning in tackling externalities. Town Plan. Rev. 78, 335-368. https://doi.org/10. 3828/tpr.78.3.5.

Mareddy, A.R., 2017. 10- Impacts on the socioeconomic environment. In: Mareddy, A.R. (Ed.), Environmental Impact Assessment: Butterworth-Heinemann, pp. 349-382.

Matthews, H.S., Lave, L.B., 2000. Applications of environmental valuation for determining externality costs†. Environ. Sci. Technol. 34, 1390-1395. https://doi.org/ 10.1021/es9907313.

Matthews, J.C., Allouche, E.N., Sterling, R.L., 2015. Social cost impact assessment of pipeline infrastructure projects. Environ. Impact Assess. Rev. 50, 196-202. https:// doi.org/10.1016/j.eiar.2014.10.001.

Najafi, M., Gokhale, S., 2005. Social costs of utility construction: a life cycle cost approach. In: Najafi, M. (Ed.), Trenchless Technology: Pipeline and Utility Design, Construction, and Renewal. McGraw-Hill, New York, pp. 2-42.

Nordhaus, W., 2014. Estimates of the social cost of carbon: concepts and results from the DICE-2013R model and alternative approaches. J. Assoc. Environ. Resour. Econ. 1, 273-312. https://doi.org/10.1086/676035.

North Cyprus State and Planning Organization, 2014. Devlet Planlama Orgutu. http:// www.devplan.org/Frame-tr.html, Accessed date: 19 June 2014.

Osei, V., 2013. The construction industry and its linkages to the Ghanaian economypolices to improve the sector's performance. Int. J. Dev. Econ. Sustain. 1, 56-72.

Pigou, A.C., 1932. The Economics of Welfare, 4th Edition ed. Macmillan, London.

Pring, R., 2004. The Philosophy of Education. Bloomsbury Publishing, London.

Rahman, S., Vanier, D., Report, Newton L.M.I.I.P., 2005. Social Cost Considerations for Municipal Infrastructure Management. National Research Council Canada, Ottawa.

Raphael, D., Rukholm, E., Brown, I., Hill-Bailey, P., Donato, E., 1996. The quality of life profile-adolescent version: background, description, and initial validation. J. Adolesc. Health 19, 366-375. https://doi.org/10.1016/S1054-139X(96)00080-8.

Read, G.F., Vickridge, I., 2004. Social or indirect costs of public utility works. In: Read, G.F. (Ed.), Sewers: Replacement and New Construction: Replacement and New Construction. Elsevier, Oxford, pp. 339.

Rombach, H.D., Basili, V.R., Selby, R.W., 1993. Experimental Software Engineering Issues: Critical Assessment and Future Directions. International Workshop, Dagstuhl Castle, Germany, September 14-18, 1992. Proceedings. Heidelberg. Springer Science \& Business Media, Germany.

Saunders, M., Lewis, P., Thornhill, A., 2016. Research Methods for Business Students, 7th ed. Pearson education.

Stigler, G.J., 1966. The Theory of Price, 3rd ed. Macmillan, New York.

United States Environmental Protection Agency, 1995. Air Emissions Factors and Quantification, AP 42. Chapter 13: Miscellaneous Sources, Section 13.2.3: Heavy Construction Operations. https://www3.epa.gov/ttnchie1/ap42/ch13/final/c13s023.pdf, Accessed date: 10 June 2019.

Verschueren, K., 2001. Handbook of Environmental Data on Organic Chemicals. vol. 1 John Wiley and Sons, Inc.

Watkins, L., 1981. Some research into the environmental impact of roads and traffic. In: Yerrell, J.S. (Ed.), Transport Research for Social and Economic Progress Proceedings of the Second World Conference on Transport Research, London.

Yeow, H.-C., Feltham, I., 2008. Case histories back analyses for the application of the observational method under Eurocodes for the SCOUT project. In: International Conference on Case Histories in Geotechnical Engineering. Missouri University of Science Technology, Arlington, Virginia.

Yu, W.D., Lo, S.S., 2005. Time-dependent construction social costs model. Constr. Manag. Econ. 23, 327-337. https://doi.org/10.1080/01446190500040281.

Yuan, Q.-M., Cui, D.-J., Jiang, W., 2013. Study on evaluation methods of the social cost of green building projects. In: Wang Jun, Jinfeng W., Yanbin, L., Fouad, R.H. (Eds.), Advances in Industrial Engineering, Information and Water Resources. WIT Press, Southampton, pp. 11

Zhou, H., Li, B., Shen, Q., Yu, S., 2017. Quantization on Social Cost of Large-Scale Construction Project Based on Emergy Analysis Method. Springer Singapore, Singapore, pp. 993-1006. 